\title{
Athletes Health during Pandemic Times: Hospitalization Rates and Variables Related to COVID-19 Prevalence among Endurance Athletes
}

Fabricio Braga da Silva, ${ }^{1,2}$ Beatriz Fonseca, ${ }^{1}{ }^{\circledR}$ Fernanda Domecg, ${ }^{\circledR}$ Marcelo Riccio Facio, ${ }^{\circledR}$ Christiane Prado ${ }^{1}{ }^{\circledR}$ Leandro Toledo, ${ }^{1}$ Walter Tuche ${ }^{3} \odot$

Laboratório de Performance Humana (LPH), ${ }^{1}$ Rio de Janeiro, RJ - Brazil.

Casa de Saúde São José, ${ }^{2}$ Rio de Janeiro, RJ - Brazil.

Walter Tuche Assessoria Esportiva, ${ }^{3}$ Rio de Janeiro, $R J$ - Brazil.

\section{Abstract}

Background: The SARS-COV2 pandemic has deeply affected the availability for training and competing for recreational and professional athletes. However, to date, the disease's course among the athletic population has not been *studied.

Objectives: To compare the observed and expected rates of hospitalization for COVID-19 and to establish relationships between demographics and sportive characteristics of an athletic sample, and the COVID-19 infection rate.

Material and Methods: This study uses cross-sectional data sampling through an online questionnaire to collect data from recreational and professional athletes. Based on self-reports, athletes were grouped in COVID-19 and Non-COVID-19 cases. To decrease detection bias for each four patients who reported being hospitalized, one additional virtual patient was added to the sample. The observed rate of hospitalization (ORH) was compared with age expected rate of hospitalization (ERH) from the literature data. A multivariate model (MM) was developed to establish independent relationships between the prevalence of COVID-19 cases and the variables mentioned above. The statistical significance level was defined for a $\mathrm{p}$-value $<0.05$.

Results: Answers from 1,701 individuals were analyzed. The COVID-19 group was comprised of 99 (5.8\%) individuals, four of whom reported having been hospitalized. ORH and ERH were respectively of 5.0\% and $18.1 \%$ $(\mathrm{p}=0.001)$. In the MM female gender (OR=2.02, 95\% CI 1.28 to 3.19), cycling (OR=2.91, 95\% CI 1.58 to 5.39), swimming $(\mathrm{OR}=2.97,95 \%$ CI 1.14 to 7.74$)$, and triathlon (OR=2.10, 95\% CI 1.13 to 3.91) were independently associated with a COVID-19 prevalence.

Conclusion: Self-reported rates of hospitalization for COVID-19 among athletes were much lower than expected. The prevalence of positive cases of COVID-19 was independently higher for cyclists, triathletes, and swimmers than for runners. (Int J Cardiovasc Sci. 2021; 34(3):274-283)

Keywords: COVID-19; Betacoronavirus, SARS-COV-2, Athletes; Exercise; Motor Activity; Hospitalization.

\section{Introduction}

Even before the SARS-COV2 pandemic had been declared by the World Health Organization (WHO), professional and recreational sportive events had already been cancelled worldwide. For the first time since the World War II, the Tokyo 2020 Olympic Games is at the top of this long list. ${ }^{1}$
Not only was competitive athletic life compromised, but the adoption of social distancing as countermeasure for SARS-COV2 spread, deeply affecting their availability to train due to the closing of indoors sport facilities and, in some places, even the prohibition of any kind of outdoor workout. $^{2,3}$

While this paper is being written, the total number of COVID-19 cases worldwide has already surpassed

Mailing Address: Fabricio Braga da Silva

Largo do Ibam, 1. Postal Code: 22271-070, Humaitá, Rio de Janeiro, RJ - Brazil

E-mail: fabriciobraga@uol.com.br 
6 million individuals, with almost 400,000 deaths. The USA is the most highly affected country (more than 1.8 million cases), followed by Brazil (more than a half million cases). ${ }^{4}$ Scientific production on COVID-19 has also increased as never before. More than 4,000 papers have already been published in the first five months of 2020, registered under the medical subheading "coronavirus infection". ${ }^{5}$ Among these are a wide range of reviews, opinions, and letters, which approach the effects of the pandemic among athletes. However, to the best of our knowledge, no original article has addressed this subject so far.

There is a biological plausibility that athletes cardiorespiratory fitness is a protective feature against severe forms of COVID-19. ${ }^{6-8}$ By contrast, the high intensity exercise usually performed by endurance athletes increases the rates of upper respiratory tract infection (URTI). ${ }^{9}$ In this new environment, we do not know if one of these two statements will prevail.

Sports organizations worldwide have been discussing the right moment to return to their competitions. ${ }^{10}$ Good practice protocols are being developed. Pre-participation screening for post COVID-19 athletes has also been published. ${ }^{11-13}$ The knowledge used in the establishment of these guidelines stems from experts' opinions, scarce information about previous coronavirus outbreaks, and some analogies made with other viral respiratory infections. To date, no specific knowledge has been developed.

Understanding the course of COVID-19 among the athletic population is of utmost importance in order to guide decision-making at individual and community levels, regarding exercise and sportive activities.

The primary goal of this research is to compare the observed and the expected rates of hospitalization for COVID-19 in an athletic sample.

The secondary goal is to establish relationships between demographics and sportive characteristics of an athletic sample, and the COVID-19 infection rate.

\section{Materials and Methods}

A cross-sectional data sampling (snowball sampling) $)^{14}$ was started by initially 78 out of 152 seeds, comprised of athletes and coaches belonging to the authors' (B.F. and E.G.) personal relationship. A google form link was sent by WhatsApp messaging, with a note explaining the importance of taking part in the survey and asking receivers to share it with other athletes and coaches. Every five days another 20 seeds were reached using the same process until the required number of COVID-19 cases was met. As soon as the target sample size was reached, the sending of the form was discontinued.

The questionnaire was developed specially for this survey, using simple language, and took 5 to 7 minutes to be fully completed. Before the first question, individuals had to read and accept the informed consent form. The first question was "Are you an endurance athlete? We consider an endurance athlete to be an individual who performs such sports as running, cycling, rowing, canoeing, triathlon, swimming, and workout 3 or more times per week with the goal of improving his sports performance". ${ }^{15,16}$ Only the response "Yes" allowed the participant to continue the questionnaire. After some demographic and sports practice questions, individuals were sent to COVID-19 questions. The first one was "Did you have COVID-19?". Three possibilities of answer were offered: "Yes, confirmed by laboratorial tests"; "No, I did not"; or "Maybe. I had COVID-19-like symptoms but didn't get to test for it". The latter option was followed by the question "In the list below, choose all the symptoms you presented". The list of symptoms represented the COVID-19-like symptoms score created by the Mozambique ministry of health and adapted by a Brazilian university. ${ }^{17}$ The score is composed by the sum of the positive signs and symptoms: fever (5 points), headache (1 point), coryza and sneezes ( 1 point), sore throat ( 1 point), dry cough (3 points), breathlessness (10 points); malaise (1 points); diarrhea (1 point); loss of smell (3 points); any contact with individual previous diagnosis for COVID-19 (10 points). Three outputs were possible: High suspicion ( $\geq 20$ points), Moderated suspicion (10 to 19 points), and Low suspicion ( $\leq 9$ points).

The COVID-19 group consisted of athletes with reported laboratorial confirmation for COVID-19 and those with highly suspicious symptoms. All the others were included in the Non-COVID-19 group. The reason to include cases without reported laboratorial confirmation is the low availability of tests in Brazil.

Except for those who reported not having COVID-19, all others were guided to the question "Were you hospitalized for COVID-19?". For those who answered "Yes", the next question was "Were you admitted to the Intensive Care Unit?".

As self-filling questionnaires were not able to detect lethal cases, we estimated based on local and literature 
data an in-hospital mortality of $20 \%$. Considering the same mortality rate among athletes, to decrease this sampling bias, for every 4 patients who reported having been hospitalized, one additional virtual patient was added.

Based on the Center of Disease Control (CDC), ${ }^{18}$ for each individual, a probability of hospitalization was attributed, based on the age group he belonged to. The lower limit of confidence interval was used to avoid the overestimation of an expected hospitalization rate. Thus, the following expected rates of hospitalization were used: $1.6 \%$ for $<20$ years old (yo), $2.5 \%$ for $20-29$ yo, $14.3 \%$ for $30-$ 39 yo, $20.8 \%$ for $40-49$ yo, $21.16 \%$ for $50-59$ yo, and 22.4 for $\geq 60$ yo. The average value for the COVID-19 group was the expected hospitalization rate. Two comparisons were performed: one for all COVID-19 groups and another only for the reported cases confirmed by a laboratory.

The prevalence for COVID-19 (positive tests and highly suspicious symptoms) were compared by gender, age group, Brazilian geographic regions, athletic level, and type of sport.

\section{Statistical Analysis and Ethics}

The sample size was calculated by estimating $10 \%$ and $20 \%$ for observed and expected hospitalization rates, respectively. A power of $80 \%$ and an alfa error of $5 \%$ were assumed, using a single proportion test based on the normal approximation to the binomial distribution. ${ }^{19}$ According to these parameters, a sample size of 86 COVID-19 cases was necessary.

Categorical variables were expressed as absolute values and percentages. Observed hospitalization rates were compared with the expected value (used as the null hypothesis value) by the test for one proportion. The 95\% confidence interval (CI) for the observed hospitalization rate was calculated using three different techniques. ${ }^{20,21}$ To stress the difference between the observed and expected rates of hospitalization, a same size simulated sample was created using the expected number of COVID-19 and non-COVID-19 cases and compared using the Chi-squared test. ${ }^{22}$ All other proportions were compared using the Chi-squared or Fisher's exact tests. CI for zero proportions were calculated according to the Hanley et al. ${ }^{23}$ method.

A multivariate logistic model was developed using positive a COVID-19 case as a dependent variable, and gender, age group, athletic level, sport, and geographic region as independent variables. Variables were included in the model when their $\mathrm{p}$-value was $\leq 5 \%$ based on chi- squared statistics, except for the age group, which was included despite statistical significance because of its acknowledged epidemiological value.

Variables were considered statistically significant when having a p-value below 5\%. All of the analysis was performed using an SPSS ${ }^{\mathrm{TM}}$ version 22.0 for Windows ${ }^{\mathrm{TM}}$ (Statistical Package for Social Sciences, IBMSPSS, IL, USA).

This research is registered in the National Committee for Ethical Research (CONEP), logged under protocol number 32179220.3.0000.5253 (https://plataformabrasil. saude.gov.br/login.jsf). Ethical approval for this study was obtained from Hospital Federal de Bonsucesso (approval number 4.054.651).

\section{Results}

Figure 1 represents the individuals included in the analysis. The questionnaire was released on May 10, 2020, and was closed in May 25, 2020, having collected 1,869 answers. After removing duplicate answers and missing data. 1,701 answers could be related to a single athlete. Among them 99 (5.8\%) athletes were included in the COVID-19 group (70 laboratory-confirmed cases and 29 highly suspicious cases) and 1,602 (\%) in the nonCOVID-19 group. Twenty of the 26 states and federal district were represented in this sample (Figure 2). Table 1 shows the distribution of gender, athletic level, age group, sport, and country's geographic region for all athletes, the COVID-19 group, and the non-COVID-19 group.

For the hospitalization analysis, as four athletes reported having been hospitalized (one cyclist and three triathletes), one virtual case was added to the analysis, thus achieving the rate of a $5 \%$ need for hospitalization among athletes. Based on NYC rates of hospitalization by age, the average expected hospitalization rate was $18.1 \pm 4.6 \%$ (SE of mean $=0.46 \%$ ) for the COVID-19 group. Figure 3-A shows the comparison between the expected and the three different types of $95 \% \mathrm{CI}$ calculation for the observed rate of hospitalization $(\mathrm{p}=0.001)$. Even considering only the 70 laboratory-confirmed positive cases, the expected rate of hospitalization was significantly higher than that observed (Figure 3-B).

A 2x2 Chi-square analysis comparing the observed and expected hospitalization rates showed significant differences either for the entire Covid-19 group (expected-observed $=13.1 \%[95 \%$ CI 4.26 to $22.23 \%$ ], $\mathrm{p}=0.003)$ as compared to the laboratory-confirmed cases (expected-observed $=11.5 \%[95 \%$ CI 0.354 to $22.78 \%], \mathrm{p}=0.046$ ). 


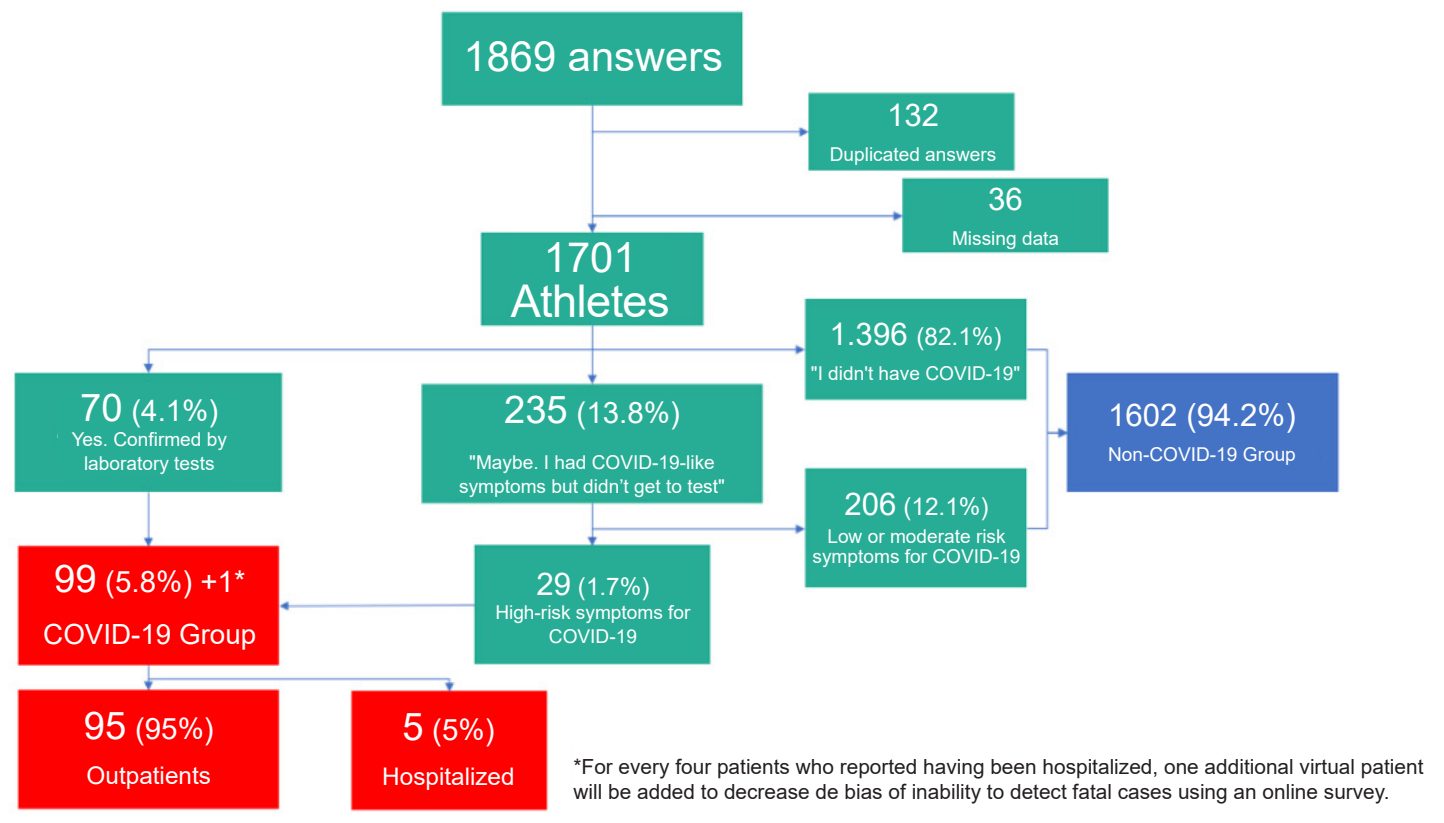

Figure 1 - Individuals enrolled in the analysis

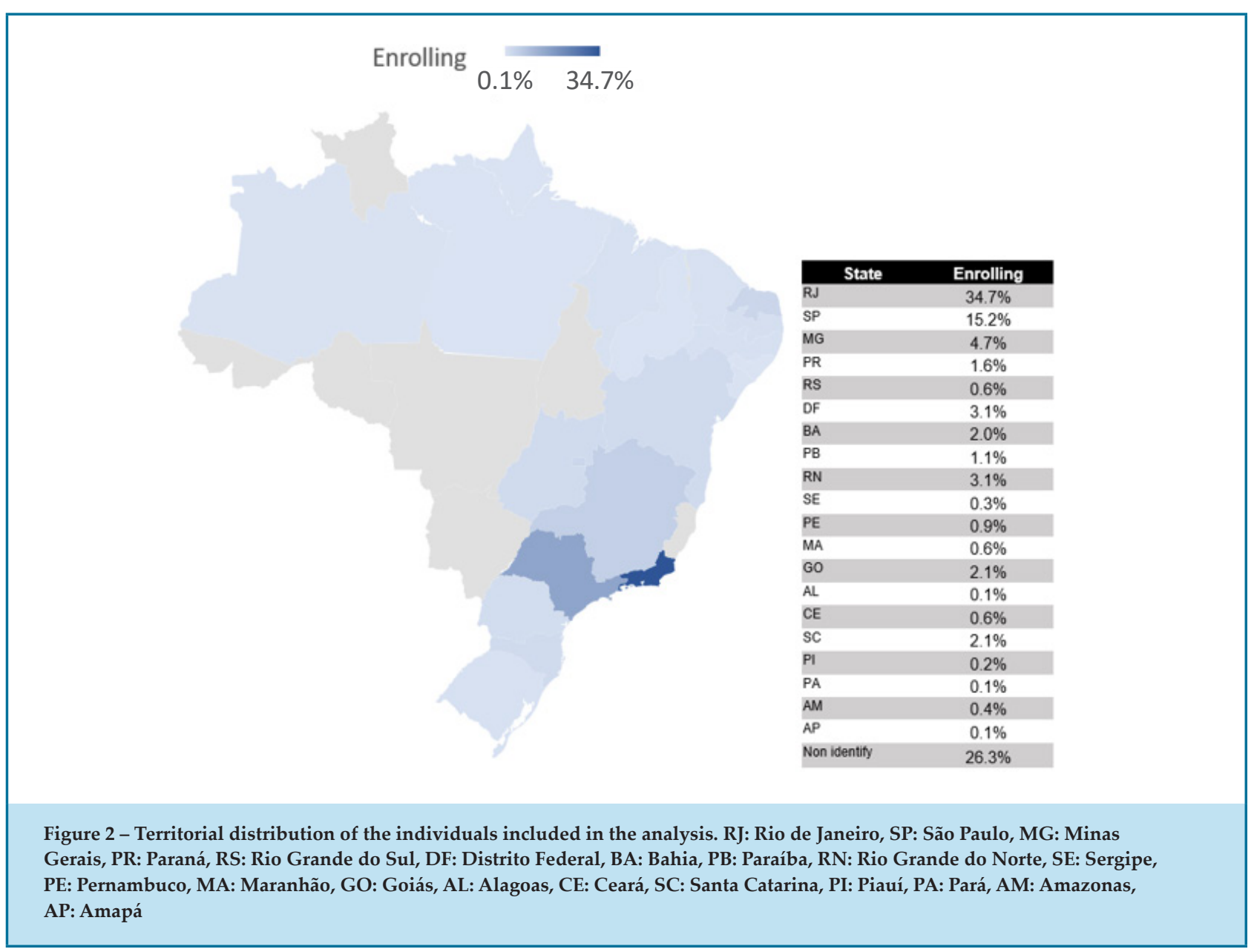


Table 1 - Distribution of the individuals included in the analysis

\begin{tabular}{|c|c|c|c|c|c|}
\hline Name & & & Total (\%) & Non-COVID-19 (\%) & COVID-19 (\%) \\
\hline & & $\mathbf{N}$ & 1701 & 1602 & 99 \\
\hline \multirow{2}{*}{ Gender } & Male & & $1181(69.4)$ & $1124(95.2)$ & $57(4.8)$ \\
\hline & Female & & $520(30.6)$ & $478(91.9)$ & $42(8.1)$ \\
\hline \multirow{6}{*}{ Sport } & Running & & $516(30.3)$ & 495(95.9) & $21(4.1)$ \\
\hline & Cycling & & $460(27)$ & 423(92) & $37(8)$ \\
\hline & Swimming & & $73(4.3)$ & $66(92.4)$ & $7(9.6)$ \\
\hline & Rowing/Canoeing & & $69(4.1)$ & $68(98.6)$ & $1(1.4)$ \\
\hline & Triathlon & & $551(32.4)$ & 518(94) & $33(6)$ \\
\hline & Others & & $32(1.9)$ & $32(100)$ & $0(0)$ \\
\hline \multirow{6}{*}{ Age Group } & $<20 y$ & & $42(2.5)$ & $42(100)$ & $0(0)$ \\
\hline & $20-29 y$ & & $121(7.1)$ & $117(96.7)$ & $4(3.3)$ \\
\hline & $30-39 y$ & & $521(30.6)$ & 489(93.9) & $32(6.2)$ \\
\hline & $40-49 y$ & & $631(37.1)$ & 592(93.8) & $39(6.2)$ \\
\hline & $50-59 y$ & & $308(18.1)$ & 291(94.5) & $17(5.5)$ \\
\hline & $\geq 60 y$ & & $78(4.6)$ & $71(91)$ & $7(9)$ \\
\hline \multirow{4}{*}{ Regions } & Southeast & & $930(54.7)$ & $849(91.3)$ & $81(8.7)$ \\
\hline & South & & $73(4.3)$ & $72(98.6)$ & $1(1.4)$ \\
\hline & Central & & $88(5.2)$ & $88(100)$ & $0(0)$ \\
\hline & North-Northeast & & $162(95.9)$ & $153(94.4)$ & $9(5.6)$ \\
\hline \multirow{2}{*}{ Athletic level } & Amatheur & & $1632(95.9)$ & 1535(94.1) & $97(5.9)$ \\
\hline & Professional & & $69(4.1)$ & $67(97.1)$ & $2(2.9)$ \\
\hline
\end{tabular}

Figures 4 A-E represent the intragroup comparisons for COVID-19 prevalence. Differences were found by gender (4.8 and $8.1 \%$, respectively, for males and females; $\mathrm{p}=0.008)$; geographic region $(8.7,1.4,0.0$, and 5.6, respectively. for the Southeast, South, Midwest, and North/Northeast; $\mathrm{p}=0.003)$ and sport $(4.1,8.0,9.6,1.4,6.0$, and $0.0 \%$, respectively, for running, cycling, swimming, rowing or canoeing, triathlon, among others) but not for age group or athletic level.

Table 2 shows the multivariate analysis for COVID-19 prevalence. The male gender, southeast region, running and age group $\geq 60$ yo were used as reference categories for gender, geographic region, sport, and age group variables, respectively. After adjustment, the female gender (OR=2.02 95\% CI 1.28 to 3.19), cycling (OR=2.91 95\% CI 1.58 to 5.39 ), swimming (OR=2.97 95\% CI 1.14 to
7.74), and triathlon (OR=2.10 95\% CI 1.13 to 3.91) were independently associated with COVID-19 prevalence.

\section{Discussion}

In this research, the rate of observed hospitalization for COVID-19 was less than half of the expected rate. Cardiorespiratory fitness has already proven beneficial in myriads of diseases, ${ }^{24,25}$ and it could be used as immunity protection until a vaccine is developed. ${ }^{26}$ Regarding infectious diseases, exercise capacity is associated with reduction on morbidity and mortality in situations ranging from seasonal URTI ${ }^{27}$ to post-operative complications resulting from major surgeries. ${ }^{28}$

Cardiorespiratory fitness has already shown benefits during viral outbreaks. Siu et al. ${ }^{29}$ demonstrated that 
A.

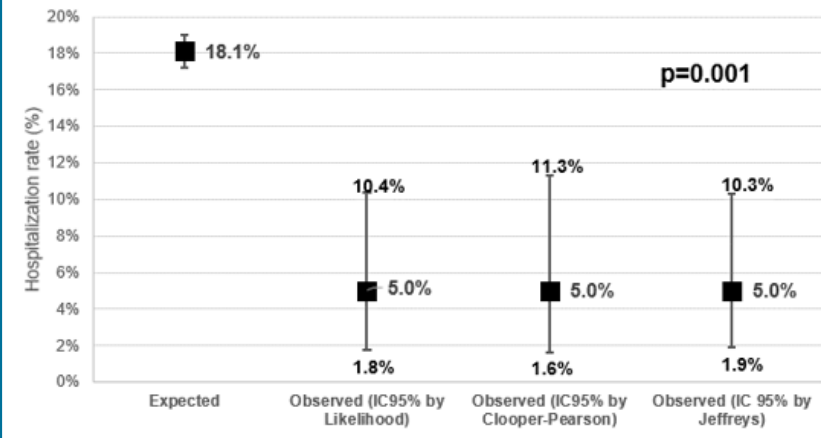

B.

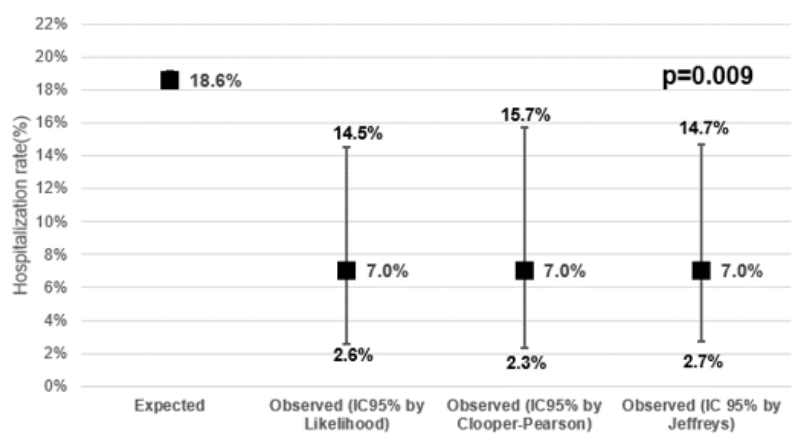

Figure 3 - Expected and observed hospitalization rates for: A-all considered positive cases, and B-only laboratory confirmed cases
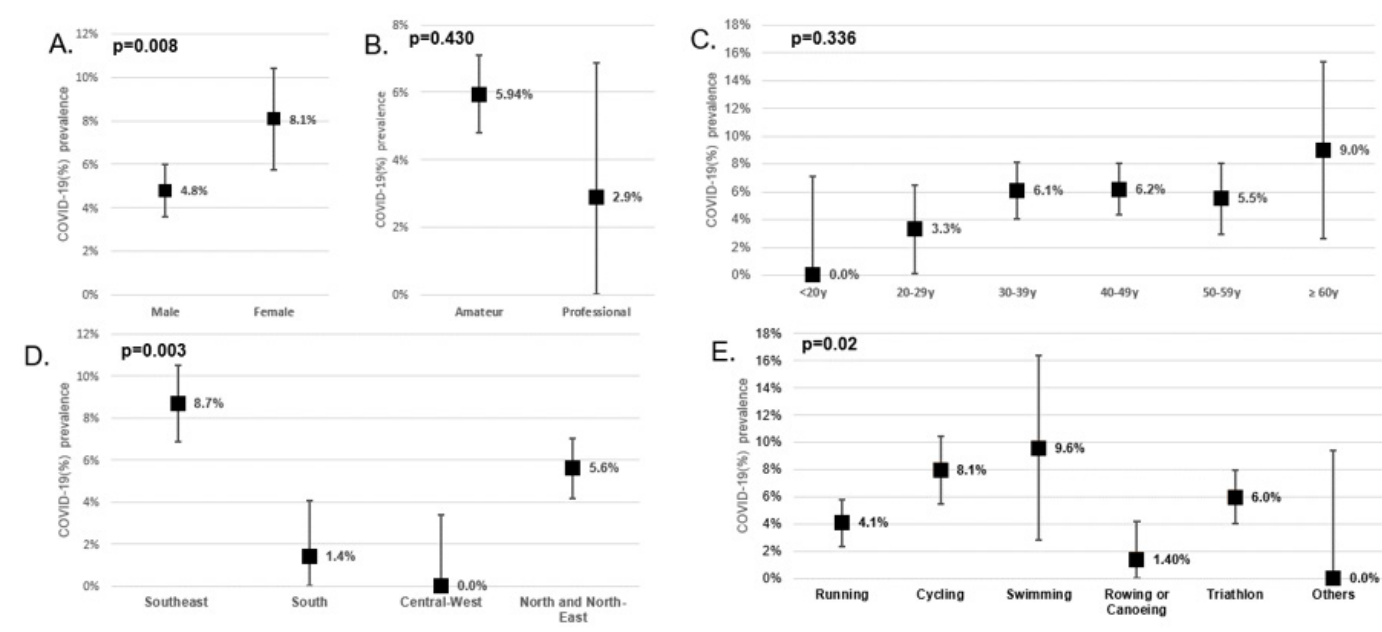

Figure 4 - Positives cases of COVID-19 per A-Gender; B-Athletic level; C-Age group; D-Geographic group and E-Sports

during 12 influenza seasons in Canada, moderately and highly active individuals younger than 65 yo had, respectively, $17 \%$ and $13 \%$ less outpatient visits for flulike-symptoms than did their non-active counterparts. Wong et al. showed a $4.2 \%$ to $6.4 \%$ reduction in mortality by H1N1 and H3N1 influenza subspecies in the 1998 Hong-Kong outbreak. ${ }^{30}$

Despite the potential immunological infection windows described in athletes after high intensity training and competitions, ${ }^{31,32}$ increasing the rate of URTI, there is no report of associating it to hard clinical endpoints. Indeed, there is some evidence that viral illnesses have little impact on training availability. ${ }^{33,34}$
Master athletes also have immunological benefits and documented reductions in respiratory infection rates. ${ }^{35}$ Minuzzi et al. showed that senior athletes (mean age 53.2 yo) keep high cell and humoral post-exercise antiinflammatory activity when compared to the controls. ${ }^{36}$ Therefore, in a wide range of performance levels and ages, being an athlete seems to decrease the risk of respiratory infections, such as COVID-19, by approximately $28 \% .{ }^{26}$

The prevalence of COVID-19 cases were 2 times higher among female athletes. Previous studies have already shown gender differences in terms of URTI in the athletic population. He et al. demonstrated that the number of respiratory illness days was higher (4.7 vs 6.8 days, $p=0.02$ ) and the duration of these episodes 
Table 2 - Multivariate analysis for COVID-19 prevalence

\begin{tabular}{|c|c|c|c|c|}
\hline & \multirow{2}{*}{$p$ value } & \multirow{2}{*}{ OR } & \multicolumn{2}{|c|}{$95 \%$ C.I } \\
\hline & & & Lower bound & Upper bound \\
\hline \multicolumn{5}{|l|}{ Gender } \\
\hline Male & & 1.00 & & \\
\hline Female & 0.003 & 2.02 & 1.28 & 3.19 \\
\hline \multicolumn{5}{|l|}{ Region } \\
\hline Southeast & 0.28 & 1.00 & & \\
\hline South & 0.097 & 0.18 & 0.03 & 1.36 \\
\hline Midwest & 1.00 & 0.00 & 0.00 & \\
\hline North and Northeast & 0.255 & 0.65 & 0.31 & 1.36 \\
\hline \multicolumn{5}{|l|}{ Sport } \\
\hline Running & 0.01 & 1.00 & & \\
\hline Cycling & 0.001 & 2.91 & 1.58 & 5.39 \\
\hline Swimming & 0.03 & 2.97 & 1.14 & 7.74 \\
\hline Rowing/Canoeing & 0.443 & 0.45 & 0.06 & 3.48 \\
\hline Triathlon & 0.02 & 2.10 & 1.13 & 3.91 \\
\hline Others & 0.998 & 0.00 & 0.00 & \\
\hline \multicolumn{5}{|l|}{ Age Group } \\
\hline$\geq 60 y$ & 0.68 & 1.00 & & \\
\hline $50-59 y$ & 0.998 & 0.00 & 0.00 & \\
\hline $40-49 y$ & 0.14 & 0.33 & 0.08 & 1.41 \\
\hline $30-39 y$ & 0.365 & 0.65 & 0.26 & 1.65 \\
\hline $20-29 y$ & 0.43 & 0.69 & 0.28 & 1.70 \\
\hline$<20 y$ & 0.191 & 0.52 & 0.20 & 1.39 \\
\hline Constant & 0.00 & 0.06 & & \\
\hline
\end{tabular}

was longer (11.6 vs 15.5 days, $\mathrm{p}=0.03$ ) in female than in male athletes. Although, the reasons behind it are not completely elucidated, it seems to be related to a decrease in oral-respiratory mucosal immunity. ${ }^{37}$

The differences in prevalence of COVID-19 positive case among sport modalities is a more complex subject. In this sample cycling, swimming and triathlon increased the odds of a COVID-19 case by 2 to 3 -fold, when compared to running.

Nieman et al. compared the inflammatory and immunological response after three days of controlled overreaching between cyclists and runners, and their impact in the URTI rate ${ }^{38}$ Despite a higher clinical and laboratorial muscle damage and inflammatory response, no difference was found either in terms of frequency or in terms of severity of URTI. Williams et al. analyzed a cohort of more than 150,000 runners and walkers. ${ }^{39}$ After a mean follow-up of 11.4 years, for each MET-hour/day increment in energy expenditure, a $10.5 \%$ reduction in pneumoniarelated death was found. Although it cannot be affirmed that the sole effect is the result of running, we were unable to find any equivalent evidence for other sports.

As proposed by Gałązka-Franta et al., multiple factors are involved in the sport risk of respiratory infection. ${ }^{40}$ 
Inter-player relationships are one of the most important. This aspect during the pandemic time may well show how athletes and sportsmen complied to social distancing.

Measuring social distancing adherence is a difficult task. Even more complex is quantifying it among athletes. Google Mobility Reports, data regarding location tracking from mobile devices, is the closest one can come to a pattern of social distancing behavior in a specific community. Analyzing the mobility trends for potential exercise locations (national parks, public beaches, marinas, dog parks, plazas, and public gardens) offers the best available information about outdoor training, and hence social distance among athletes. Figure 5 shows mobility weekly trends in those areas in the 20 Brazilian states considered in this study, as compared to two other South American countries (Chile and Argentina) and two Europeans countries (Italy and Spain), from the beginning of March to the end of April. In addition to the fact that during this period these Brazilian regions underwent a $70 \%$ reduction in mobility, ${ }^{41}$ this mobility reduction was considered low when compared to other countries. Therefore, it is suitable to assume that a non-negligible number of people continued to exercise outdoors.

Concerns about cyclists respiratory health caused by inhalation of fine and ultrafine particulate matter have already been raised by some studies. ${ }^{42-45}$ Strak et al. found a significant change in lung function after cycling during rush hours.

If a cyclist (or even a triathlete during cycling training) inhales a great amount of air particles, respiratory SARS-
COV2 infected droplets exhaled by another athlete in the same pack could also be inhaled. Blocken et al., in a simulated model, raised the possibility that droplets exhaled by a cyclist moving at $30 \mathrm{~km} / \mathrm{h}$ could travel in the air for up to $20 \mathrm{~m} \cdot{ }^{46,47}$ All this together could explain the increased odds for COVID-19 in cyclists and triathletes when compared to runners.

In this sample, $15.8 \%$ of the swimmers were older than 60 yo vs. $4.3 \%$ from other sports ( $p<0.001)$. Positive cases of COVID-19 were $9.0 \%$ in this age group and $5.7 \%$ at $<60$ yo. Not only is the severity of COVID-19 higher in the elderly, but the disease prevalence is as well. This could account for the independent relationship between COVID-19 cases and swimmers.

This study has a number of limitations. First, despite the measures to improve the sample's diversity, a true picture of the Brazilian population was not achieved. Not all pf the states were represented, and their proportions did not match Brazilian demographics. As a self-report survey, we could not guarantee that all individuals could self-recognize their symptoms nor understand what a laboratory-confirmed case is. However, Brazilian health agencies have been promoting educational campaigns to improve the recognition of symptoms and interpretations of test results. Unfortunately, there was also a lack local public data to compare the rates of hospitalization. Although some similarities were found between Brazilian and New York City data (mortality, mechanical ventilation, need for ICU), we could not guarantee the same for hospital admission rates. Athletes

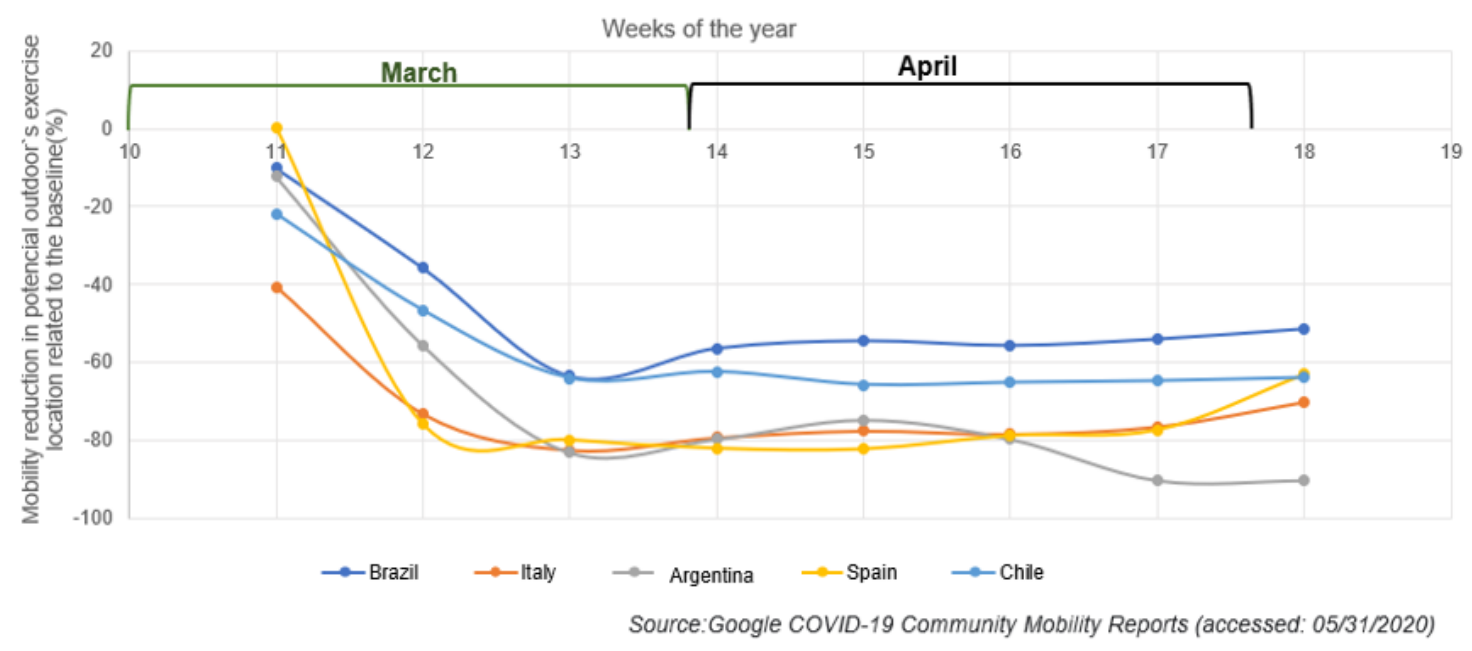

Figure 5 - Comparisons of mobility reduction among Brazil, Chile, Argentina, Italy, and Spain throughout March and April 2020 
hospitalized at the time when this survey was ongoing may have underestimated the rate of hospitalization among athletes. Finally, the numbers of variables related to infectiousness of SARS-COV-2 are much larger than we have collected here.

\section{Conclusion}

Based in this cross-sectional analysis of athlete selfreports, rates of hospitalization among these individials were much lower than expected. After adjustments, the COVID-19 prevalence was higher for cyclists, triathletes, and swimmers than for runners. No age, regional, or athletic level effects were found. Many social, biological, and environmental assumptions could explain these results. A great number of questions were raised by this research. In a world which claims to restore recreational and professional sports activities, answering these questions should be the aim of future studies.

\section{Potential Conflict of Interest}

No potential conflict of interest relevant to this article was reported.

\section{References}

1. Toresdahl BG, Asif IM. Coronavirus disease 2019 (COVID-19): considerations for the competitive athlete. Sports Health. 2020;12(3):221-4.

2. Timpka T. Sports health during the SARS-Cov-2 pandemic. Sports Med. 2020;50(8):1413-6.

3. Nyenhuis SM, Greiwe J, Zeiger JS, Nanda A, Cooke A. Exercise and fitness in the age of social distancing during the COVID-19 pandemic. J Allergy Clin Immunol Pract. 2020;8(7):2152-5.

4. Worldometer [Internet]. Coronavirus Update (Live): 6,206,037 Cases and 371,916 Deaths from COVID-19 Virus Pandemic.. [citado 31 maio 2020 ]. Disponível em:: https://www.worldometers.info/coronavirus/

5. PubMed [Internet]. "Coronavirus Infections"[Mesh] - Search Results - [citado 31 maio 2020]. Disponível em: https://pubmed.ncbi.nlm.nih. gov $/$ ?term $=\% 22$ Coronavirus+Infections $\% 22 \% 5$ BMesh $\% 5$ D\&filter=yea rs.2020-2020

6. Mohamed AA, Alawna M. Role of increasing the aerobic capacity on improving the function of immune and respiratory systems in patients with coronavirus (COVID-19): a review. Diabetes Metab Syndr Clin Res Rev. 2020;14(4):489-96.

7. Hamer M, Kivimäki M, Gale CR, Batty GD. Lifestyle risk factors for cardiovascular disease in relation to COVID-19 hospitalization: a community-based cohort study of 387109 adults in UK. medRxiv. 2020 May 13.

8. Ahmed I. COVID-19 - does exercise prescription and maximal oxygen uptake (VO2 max) have a role in risk-stratifying patients? Clin Med. 2020;20(3):282-4.

\section{Sources of Funding}

This study was funded by own resources.

\section{Study Association}

This study is not associated with any thesis or dissertation work.

\section{Ethics Approval and Consent to Participate}

This study was approved by the Ethics Committee of the Hospital Federal de Bonsucesso under the protocol number 4.054.651. All the procedures in this study were in accordance with the 1975 Helsinki Declaration, updated in 2013. Informed consent was obtained from all participants included in the study.

\section{Author Contributions}

Conception and design of the research: Silva $\mathrm{FB}$, T Walter. Acquisition of data: Silva FB, Fonseca B, Domecg F, Prado C, Facio MR, Toledo L. Analysis and interpretation of the data: Silva FB, Fonseca B. Statistical analysis: Silva FB. Critical revision of the manuscript for intellectual content: Silva FB.

9. Hull JH, Loosemore M, Schwellnus M. Respiratory health in athletes: facing the COVID-19 challenge. Lancet Respir Med. 2020;8(6):557-8.

10. New York Times [Internet]. When are sports coming back from the coronavirus pandemic? [citado 12 maio 2020]. Disponível em: https:// www.nytimes.com/article/coronavirus-sports-leagues-returningcanceled.html

11. Baggish BAL, Drezner JA, Kim JH, Martinez MW. Resurgence of sport in the wake of COVID-19: cardiac considerations in competitive athletes. Br J Sports Med. 2020;54(19):1130-1.

12. Nieß A, Bloch W, Friedmann-Bette B, Grim C, Halle M, Hirschmüller A, et al. Position stand: return to sport in the current coronavirus pandemic (SARS-CoV-2 / COVID-19). Ger J Sport Med. 2020;71(5):E1-4.

13. Schellhorn $P$, Klingel K, Burgstahler C. Return to sports after COVID-19 infection. Eur Heart J. 2020 May 20;ehaa448. [Epub ahead of print].

14. Kirchherr J, Charles K. Enhancing the sample diversity of snowball samples: recommendations from a research project on anti-dam movements in Southeast Asia. PLoS One. 2018;13(8):e0201710.

15. McKinney J, Velghe J, Fee J, Isserow S, Drezner JA. Defining athletes and exercisers. Am J Cardiol. 2019;123(3):532-5.

16. MacMahon C, Parrington L. Not all athletes are equal, but don't call me an exerciser: response to Araujo and Scharhag. Scand J Med Sci Sports. 2017;27(8):904-6.

17. Comitê de Monitoramento do Coronavírus [Internet]. Medidas preventivas: orientações sobre o coronavírus nas crianças. [citado 12 maio 2020]. Disponível em: https://sites.unipampa.edu.br/coronavirus/ prevencao/ 
18. Bialek S, Boundy E, Bowen V, Chow N, Cohn A, Dowling N, et al. Severe outcomes among patients with coronavirus disease 2019 (COVID-19) - United States, February 12-March 16, 2020. MMWR Morb Mortal Wkly Rep [Internet]. 2020 Mar 27;69(12):343-6. [citado 13 maio 2020 Disponível em: http://www.cdc.gov/mmwr/volumes/69/wr/mm6912e2. htm?s_cid=mm6912e2_w

19. Rosner B. Hypothesis testing: one-sample inference - one-sample inference for a binomial proportion. In: Fundamentals of biostatistics [Internet]. 4th ed. Belmont, Calif: Duxbury Press; 1995. p. 249-59. [citado 30 maio 2020]. Disponível em: https://iucat.iu.edu/iupui/1112772

20. Tony Cai T. One-sided confidence intervals in discrete distributions. J Stat Plan Inference. 2005 Apr 1;131(1):63-88.

21. Clopper CJ, Pearson ES. The use of confidence or fiducial limits illustrated in the case of the binomial Biometrika. 1934;26(4):404-13.

22. Newcombe RG, Altman DG. Proportions and their differences. In: Statistics with confidence. New Jersey: Wiley; 2000. p. 45-57.

23. Hanley JA, Lippman Hand A. If nothing goes wrong, is everything all right?: Interpreting zero numerators. JAMA. 1983 Apr 1;249(13):1743-5

24. Pedersen BK, Saltin B. Exercise as medicine - evidence for prescribing exercise as therapy in 26 different chronic diseases. Scand J Med Sci Sport. 2015;25(Suppl 3):1-72

25. Mandsager K, Harb S, Cremer P, Phelan D, Nissen SE, Jaber W. Association of cardiorespiratory fitness with long-term mortality among adults undergoing exercise treadmill testing. JAMA Netw Open. 2018;1(6):e183605.

26. Laddu DR, Lavie CJ, Phillips SA, Arena R. Physical activity for immunity protection: inoculating populations with healthy living medicine in preparation for the next pandemic. Prog Cardiovasc Dis. 2020 Apr 9. [Epub ahead of print].

27. Matthews CE, Ockene IS, Freedson PS, Rosal MC, Merriam PA, Heber JR. Moderate to vigorous physical activity and risk of upper-respiratory tract infection. Med Sci Sports Exerc. 2002;34(8):1242-8.

28. Snowden CP, Prentis JM, Anderson HL, Roberts DR, Randles D, Renton M, et al. Submaximal cardiopulmonary exercise testing predicts complications and hospital length of stay in patients undergoing major elective surgery. Ann Surg. 2010;251(3):535-41.

29. Siu E, Campitelli MA, Kwong JC. Physical Activity and Influenzacoded outpatient visits, a population-based cohort study. PLoS One. 2012;7(6):e39518.

30. Wong CM, Lai HK, Ou CQ, Ho SY, Chan KP, Thach TQ, et al. Is exercise protective against influenza-associated mortality? PLoS One. 2008;3(5):e2108.

31. Valtonen M, Waris M, Vuorinen T, Eerola E, Hakanen AJ, Mjosund $\mathrm{K}$, et al. Common cold in team Finland during 2018 Winter Olympic Games (PyeongChang): epidemiology, diagnosis including molecular point-of-care testing (POCT) and treatment. Br J Sports Med. 2019 Sep 1;53(17):1093-8.

32. Nieman DC, Wentz LM. The compelling link between physical activity and the body's defense system. J Sport Heal Sci. 2019;8(3):201-17.
33. Orhant E, Carling C, Cox A. A three-year prospective study of illness in professional soccer players. Res Sport Med. 2010 Jul;18(3):199-204.

34. Jaworski CA, Rygiel V. Acute illness in the athlete. Clin Sports Med. 2019;38(4):577-95.

35. Shephard RJ, Kavanagh T, Mertens DJ, Qureshi S, Clark M. Personal health benefits of masters athletics competition. Br J Sports Med. 1995 Sep 1;29(1):35-40.

36. Minuzzi LG, Rama L, Bishop NC, Rosado F, Martinho A, Paiva A, et al. Lifelong training improves anti-inflammatory environment and maintains the number of regulatory $\mathrm{T}$ cells in masters athletes. Eur J Appl Physiol. 2017 Jun 1;117(6):1131-40.

37. He CS, Bishop NC, Handzlik MK, Muhamad AS, Gleeson M. Sex differences in upper respiratory symptoms prevalence and oralrespiratory mucosal immunity in endurance athletes. Exerc Immunol Rev. 2014 Jan 1;20:8-22.

38. Nieman DC, Luo B, Dréau D, Henson DA, Shanely RA, Dew D, et al. Immune and inflammation responses to a 3-day period of intensified running versus cycling. Brain Behav Immun. 2014 Jul;39:180-5.

39. Williams PT. Dose-response relationship between exercise and respiratory disease mortality. Med Sci Sports Exerc. 2014;46(4):711-7.

40. Gałązka-Franta A, Jura-Szołtys E, Smółka W, Gawlik R. Upper respiratory tract diseases in athletes in different sports disciplines. J Hum Kinet. 2016;53:99-106.

41. Bergman NK, Fishman R. Mobility reduction and covid-19 transmission rates. medRxiv. 2020 Jun 2;2020.05.06.20093039.

42. Jarjour S, Jerrett M, Westerdahl D, Nazelle A, Hanning C, Daly L, et al. Cyclist route choice, traffic-related air pollution, and lung function: a scripted exposure study. Environ Health. 2013 Feb 7;12:14.

43. Park HY, Gilbreath S, Barakatt E. Respiratory outcomes of ultrafine particulate matter (UFPM) as a surrogate measure of near-roadway exposures among bicyclists. Environ Health. 2017 Feb 8;16:6.

44. Strak M, Boogaard H, Meliefste K, Oldenwening M, Zuurbier M, Brunekreef $\mathrm{B}$, et al. Respiratory health effects of ultrafine and fine particle exposure in cyclists. Occup Environ Med. 2010 Feb 1;67(2):118-24.

45. Cole-Hunter T, Jayaratne R, Stewart I, Hadaway M, Morawska L, Solomon C. Utility of an alternative bicycle commute route of lower proximity to motorised traffic in decreasing exposure to ultra-fine particles, respiratory symptoms and airway inflammation - a structured exposure experiment. Environ Health. 2013 Apr 8;12:29.

46. Blocken B, Malizia F, Van Druenen T, Marchal T. Towards aerodynamically equivalent COVID-19 $1.5 \mathrm{~m}$ social distancing for walking and running. [Preprint]. Disponível em: http://www.urbanphysics.net/Social\%20 Distancing\%20v20_White_Paper.pdf

47. Blocken B, Marchal T. Towards aerodynamically equivalent COVID-19 $1.5 \mathrm{~m}$ social distancing for walking and running: questions and answers [Internet]. [citado 21 jun 2020]. Disponível em: http://www.urbanphysics. net/Questions_and_Answers.pdf 